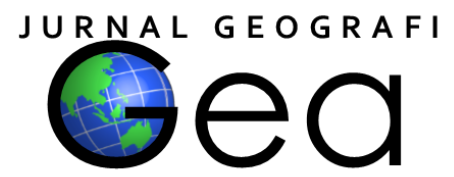

\title{
ALIH FUNGSI MATA PENCAHARIAN PENDUDUK DARI SAYURAN KE TANAMAN KOPI DI DESA MEKARJAYA KECAMATAN ARJASARI KABUPATEN BANDUNG
}

\author{
Saepuloh $^{1}$, Suryana ${ }^{2}$, Ajat Sudrajat ${ }^{3}$ \\ ${ }^{1,2,3}$ Program Studi Pendidikan Geografi, Fakultas Keguruan dan Ilmu Pendidikan, Universitas \\ Bale Bandung \\ 1uzun.saefuloh.5@gmail.com
}

\begin{abstract}
Agriculture is a sector that is used as the main livelihood of Indonesian people. This study aims to determine the factors causing changes in people's livelihoods as vegetable farmers to coffee farmers in Mekarjaya Village, Arjasari District, Bandung Regency. The research method used is descriptive with the data collection techniques used are observation, structured interviews, questionnaires, and documentation. The population is 107 households, while the sample is 52 households. The results of this study indicate that the causes of changes in the livelihoods of vegetable farmers to coffee farmers are: (1) Rainfall of 3,545 $\mathrm{mm} /$ year in accordance with Arabica coffee growth requirements, (2) Land height of 1,200 meters above sea level, (3) PERHUTANI regulations that make coffee plants as protective plants for forest erosion, (4) Increased income of farmers after becoming a coffee farmer, (5) Income from the sale of coffee can meet daily needs including education and health, (6) Farmer's income is influenced by the way marketing of coffee production results.
\end{abstract}

Keywords: farmers, coffee, vegetables

\begin{abstract}
ABSTRAK
Pertanian merupakan sektor yang dijadikan sebagai mata pencaharian utama masyarakat Indonesia. Penelitian ini bertujuan untuk mengetahui faktor penyebab perubahan mata pencaharian penduduk sebagai petani sayuran menjadi petani kopi di Desa Mekarjaya Kecamatan Arjasari Kabupaten Bandung. Metode penelitian yang digunakan adalah deskriptif dengan teknik pengumpulan data yang digunakan yaitu observasi, wawancara terstruktur, kuesioner, dan dokumentasi. Jumlah populasi yaitu $107 \mathrm{KK}$, sedangkan sampel sebanyak $52 \mathrm{KK}$. Hasil penelitian ini menunjukkan bahwa penyebab perubahan mata pencaharian masyarakat petani sayuran menjadi petani kopi adalah: (1) Curah hujan $3.545 \mathrm{~mm} /$ tahun yang sesuai dengan syarat tumbuhnya kopi arabika, (2) Ketinggian lahan $1.200 \mathrm{mdpl}$, (3) Aturan PERHUTANI yang menjadikan tanaman kopi sebagai tanaman pelindung erosi hutan, (4) Peningkatan pendapatan petani setelah menjadi petani kopi, (5) Pendapatan dari penjualan kopi dapat memenuhi kebutuhan sehari-hari termasuk pendidikan dan kesehatan, (6) Pendapatan petani dipengaruhi oleh cara pemasaran hasil produksi kopi.
\end{abstract}

Kata Kunci: Alih Fungsi, Mekarjaya, Petani Kopi, Petani Sayuran

\section{PENDAHULUAN}

Sektor pertanian merupakan salah satu sumber mata pencaharian utama Negara Indonesia (Sumaatmaja, 1989; hlm 166).
Pertanian merupakan dasar kehidupan ekonomi manusia. Pada lahan pertanian yang berada di dataran tinggi, sebagian besar petani memanfaatkan lahan tersebut untuk ditanami 
tanaman jenis sayuran. Hal tersebut terjadi di salah satu daerah yang ada di Kabupaten Bandung yaitu tepatnya di Desa Mekarjaya Kecamatan Arjasari. Hampir 90\% petani yang ada di Desa tersebut memanfaatkan lahan pertanian yang dimilikinya untuk bertani tanaman jenis sayuran seperti kol, cabai, tomat, dan sebagainya. Berikut merupakan data penduduk berdasarkan jenis mata pencahariannya di Desa Mekarjaya tahun 2018.

Tabel 1. Data penduduk berdasarkan jenis mata pencaharian di Desa Mekarjaya

\begin{tabular}{ccc}
\hline No. & $\begin{array}{c}\text { Jenis Mata } \\
\text { Pencaharian }\end{array}$ & $\begin{array}{c}\text { Jumlah } \\
\text { Penduduk }\end{array}$ \\
\hline 1. & Petani & 415 orang \\
\hline 2. & TNI/POLRI & 3 orang \\
\hline 3. & Pensiunan & 27 orang \\
\hline 4. & Peternak & 165 orang \\
\hline \multicolumn{3}{r}{ Sumber: Monografi Data Dinamis Kependudukan } \\
\end{tabular}

Berdasarkan tabel diatas, dapat dilihat bahwa pertanian menyumbang tenaga kerja yang cukup banyak yaitu sebanyak 415 orang petani. Jumlah tersebut menandakan bahwa sektor pertanian merupakan mata pencaharian utama penduduk di Desa Mekarjaya. Hal tersebut dikarenakan sebagian besar lahan yang ada di Desa Mekarjaya yaitu lahan pertanian yang cukup produktif. Tetapi, pemanfaatan lahan tersebut sebagian besar masih terpaku pada tanaman sayuran. Padahal income dari tanaman sayuran kurang maksimal untuk pembiayaan kehidupan sehari-hari. Selain itu, dalam pemasarannya, terdapat beberapa kendala yaitu pada konsumen yang selalu menghendaki sayuran dalam keadaan segar, rantai pemasaran yang panjang, permintaan pasar yang tidak terkendali (tidak teratur dan tidak menerus) serta pengadaan sayuran yang terbatas.

Berkaca dari keadaan di atas, terdapat beberapa petani kopi yang tergabung dalam Lembaga Masyarakat Daerah Hutan (LMDH), mampu membuktikan bahwa kopi mampu menghasilkan pendapatan yang tinggi dan dapat menjamin kesejahteraan perekonomian bagi masyarakat menyebabkan para petani sayuran secara perlahan beralih ke tanaman kopi. Selain itu, adanya peraturan mengenai pemanfaatan lahan perkebunan terutama wilayah hutan menyebabkan para petani harus beralih pada tanaman-tanaman yang dapat tetap menjaga kelestarian dan keseimbangan wilayahnya.

Menurut pendapat salah satu petani kopi arabika di Desa Mekarjaya mengatakan bahwa bertani kopi membutuhkan waktu yang cukup lama untuk bisa sampai ke tahap panen. Dalam pemasarannya tidak seperti sayuran, kopi dalam jumlah banyak dapat dijual ke eksportir atau pengusaha yang bergerak di bidang kopi (seperti kafe, warkop dan lain-lain). Harga jual kopi yang akan dijual dapat disesuaikan dengan harga jual kopi dipasaran atau juga dapat disesuaikan dengan cara pengolahan kopi yang digunakan. Oleh karena itu, menjadi petani kopi dapat dikatakan lebih menguntungkan.

Desa Mekarjaya berada di kaki Gunung Malabar sehingga hal tersebut sangat mendukung tumbuhnya tanaman kopi arabika. Ketinggian lahan sangat berpengaruh terhadap kualitas biji kopi yang akan dihasilkan. letaknya yang berada di bawah kaki gunung api yang sempat erupsi juga menyebabkan lahannya memiliki kandungan unsur hara dan mineral yang baik. Lahan yang kaya akan unsur hara sangat menghendaki tumbuhnya tanaman kopi arabika. Kualitas kopi yang dihasilkan juga dipengaruhi oleh temperatur udara dan intensitas cahaya matahari yang seimbang. Melihat hal tersebut, secara perlahan penduduk khususnya mulai beralih untuk menjadi petani kopi.

Berdasarkan latar belakang yang telah di kemukakan sebelumya, maka dapat disusun rumusan masalah yang akan menjadi acuan dalam penelitian ini yaitu "Faktor apakah secara geografis yang mempengaruhi masyarakat untuk mengadakan alih fungsi mata pencaharian dari pertanian sayuran ke tanaman kopi?".

Penelitian yang akan dilakukan ini bertujuan untuk: (1) mengetahui faktor-faktor secara geografis yang mempengaruhi alih fungsi mata pencaharian dari sayuran ke tanaman kopi di Desa Mekarjaya; (2) mengetahui perekonomian petani kopi di Desa Mekarjaya; (3) mengetahui proses budi daya tanaman kopi; (4) mengetahui jumlah petani kopi di Desa Mekarjaya; 
mengetahui luas wilayah keseluruhan perkebunan kopi di Desa Mekarjaya.

\section{METODE PENELITIAN}

Metode penelitian yang digunakan ialah metode penelitian deskriptif yaitu penelitian yang berusaha mendeskripsikan suatu gejala, peristiwa, kejadian yang terjadi pada saat sekarang. Metode penelitian ini lebih mengarah pada pengungkapan suatu masalah atau keadaan yang sebagaimana adanya sesuai fakta yang ada.

Teknik pengumpulan data yang digunakan dalam penelitian ini adalah: (1) Observasi; (2) Kuesioner tertutup; (3) Teknik dokumentasi, digunakan untuk memperoleh data dinamis Desa serta data petani kopi yang didapatkan dari Desa dan Lembaga Masyarakat Desa Hutan (LMDH); (4) Wawancara.

Teknik pengolahan data yang digunakan dalam penelitian ini adalah teknik pengolahan data kuantitatif yang terdiri dari beberapa tahapan yaitu editing, koding dan frekuensi, dan tabulasi data yang terdiri dari proses penyusunan dan analisis data. Selanjutnya hasil penelitian dideskripsikan secara sistematis sebagai laporan hasil penelitian lalu diinterpretasikan untuk mendapatkan makna yang lebih jelas dari hasil penelitian.

Dalam suatu penelitian, tidak akan luput dari populasi dan sampel. Menurut Tikka P (2005, hlm 24) populasi adalah himpunan atau objek yang banyaknya terbatas atau tidak terbatas. Sedangkan menurut Arifin (2012, hlm 32) populasi adalah keseluruhan objek yang diteliti, baik berupa orang, benda, kejadian, nilai maupun hal-hal yang terjadi. Dalam penelitian ini, populasinya ialah keseluruhan kepala keluarga yang bermata pencaharian sebagai petani kopi di Desa Mekarjaya Kecamatan Arjasari Kabupaten Bandung tahun 2019 dengan jumlah 107 orang petani kopi arabika.

Menurut Arifin (2012, hlm 132) sampel yaitu sebagian dari populasi yang akan diselidiki atau dapat juga dikatakan bahwa sampel adalah sebagian populasi dalam bentuk mini. Sampel yang diambil dari populasi jumlah KK sebagai petani kopi setiap RW yang paling banyak yaitu RW 07 dengan $21 \mathrm{KK}$, RW 08 sebanyak $41 \mathrm{KK}$, dan
RW 11 sebanyak 27 KK. Ketiga RW tersebut memiliki jumlah petani kopi terbanyak dibandingkan dengan RW yang lainnya di Desa Mekarjaya. Sampel yang diperoleh menggunakan teknik purposive sampling yaitu RW 07 diambil sampel 17 orang, RW 08 sebanyak 29 orang, dan RW 11 sebanyak 21 orang. Maka jumlah sampel penelitian secara keseluruhan ialah 67 orang petani kopi di Desa Mekarjaya.

\section{HASIL PENELITIAN DAN PEMBAHASAN}

\section{A. Kondisi Geografis Desa Mekarjaya}

\section{Letak dan Luas Wilayah}

Desa Mekarjaya merupakan salah satu Desa yang berada di wilayah Kecamatan Arjasari Kabupaten Bandung Provinsi Jawa Barat. Secara astronomis, Desa Mekarjaya terletak pada posisi 07,06933 LS dan 107,62773 BT dengan ketinggian sekitar 7001.200 meter di atas permukaan laut. Batasbatas wilayahnya terdiri dari: (a) Utara: Desa Baros; (b) Timur: Desa Mangunjaya; (c) Selatan: Tanah Kehutanan; (d) Barat: Desa Baros. Desa Mekarjaya memiliki luas sekitar 722 Ha yang terbagi atas tanah sawah dengan luas $110 \mathrm{Ha}$, tanah kering berupa pekarangan dan tegal kebun seluas $212 \mathrm{Ha}$, tanah basah $16 \mathrm{Ha}$, tanah hutan $400 \mathrm{Ha}$, dan tanah keperluan fasilitas umum seluas 6,77 Ha.

\section{Kondisi Geomorfologi Desa Mekarjaya}

Desa Mekarjaya merupakan sebuah daerah yang berada di kawasan kaki Gunung Malabar. Bentuk tanah di daerah Desa Mekarjaya dapat dikategorikan menjadi tiga, yaitu datar sampai berombak sekitar $15 \%$ dari luas wilayah, berombak sampai berbukit sekitar $35 \%$ dan sisanya sekitar $50 \%$ tanah berbentuk bukit sampai bergunung yang dimanfaatkan para petani untuk bercocok tanaman kopi.

\section{Kondisi Iklim}

Berdasarkan klasifikasi iklim Junghuhn menjelaskan bahwa, Desa Mekarjaya termasuk ke dalam zona iklim sedang dengan rata-rata ketinggian 600-1.200 meter dari ketinggian air laut dengan kondisi suhu yang masih tetap terasa hangat yaitu sekitar $20^{\circ} \mathrm{C}$ 
sehingga tanaman yang dapat tumbuh cukup beragam salah satunya tanaman kopi. Bila diaplikasikan pada klasifikasi iklim menurut Junghuhn maka pembagian daerah iklim dapat dilihat pada tabel 2 .

Tabel 2. Klasifikasi Iklim Menurut Junghuhn

\begin{tabular}{|c|c|c|c|}
\hline Iklim & $\begin{array}{c}\text { Elevasi } \\
\text { (mdpl) }\end{array}$ & Suhu & $\begin{array}{c}\text { Jenis } \\
\text { Tanaman } \\
\end{array}$ \\
\hline Panas/Tropis & $0-600$ & $\begin{array}{l}22^{\circ} \mathrm{C}- \\
26,3^{\circ} \mathrm{C}\end{array}$ & $\begin{array}{l}\text { Padi, } \\
\text { jagung, } \\
\text { kopi, } \\
\text { kelapa, } \\
\text { tembakau, } \\
\text { tebu, dan } \\
\text { karet }\end{array}$ \\
\hline Sedang & $\begin{array}{l}600- \\
1.500\end{array}$ & $\begin{array}{l}17,1^{\circ} \mathrm{C}- \\
22^{\circ} \mathrm{C}\end{array}$ & $\begin{array}{l}\text { Padi, } \\
\text { tembakau, } \\
\text { teh, kopi, } \\
\text { kina, dan } \\
\text { sayur- } \\
\text { sayuran }\end{array}$ \\
\hline Sejuk & $\begin{array}{l}1.500- \\
2.500\end{array}$ & $\begin{array}{l}11,1^{\circ} \mathrm{C}- \\
17,1^{\circ} \mathrm{C}\end{array}$ & $\begin{array}{l}\text { Kopi, teh, } \\
\text { ina, dan } \\
\text { sayur- } \\
\text { sayuran }\end{array}$ \\
\hline Dingin & $>2.500$ & $\begin{array}{l}6,2^{\circ} \mathrm{C}- \\
11,1^{\circ} \mathrm{C}\end{array}$ & $\begin{array}{l}\text { Tidak ada } \\
\text { tanaman } \\
\text { budi daya }\end{array}$ \\
\hline
\end{tabular}

Sumber: Rafi'i, S. 2010. Meteorologi dan Klimatologi

Jika dilihat pada tabel klasifikasi iklim di atas, seperti diketahui bahwa ketinggian Desa Mekarjaya yaitu sekitar 1.200 mdpl maka dapat diketahui bahwa Desa Mekarjaya termasuk ke dalam klasifikasi iklim daerah sedang. Berdasarkan hal tersebut maka kopi merupakan tanaman yang cocok ditanam atau dibudidayakan di Desa Mekarjaya.

Curah hujan merupakan salah satu unsur iklim sebagai syarat tumbuh tanaman kopi yaitu yang mana tanaman kopi dapat tumbuh optimal pada daerah dengan curah hujan tahunan sekitar 2.000-3.000 mm/tahun. Di Desa Mekarjaya sendiri curah hujan yang dimiliki pertahunnya yaitu $3545 \mathrm{~mm} /$ tahun, hal tersebut melebihi syarat jumlah curah hujan bagi tanaman kopi per tahun pada umumnya. Tetapi, karena suhu wilayah perkebunan yang cukup hangat, tanaman kopi akan tetap dapat tumbuh dengan baik.

\section{Topografi}

Terkait dengan ketinggian suatu daerah, tanaman kopi dapat tumbuh optimal pada daerah yang memiliki ketinggian 700-1.700 mdpl. Desa Mekarjaya termasuk daerah bergelombang atau berbukit karena memiliki ketinggian sekitar $1.200 \mathrm{mdpl}$ dengan $15 \%$ datar hingga berombak, 35\% berombak hingga berbukit, dan $50 \%$ berbukit hingga bergunung.

\section{B. Analisis Hasil Penelitian \\ 1. Luas dan bentuk lahan garapan}

Luas garapan yang digarap warga dapat dilihat pada tabel 3 .

Tabel 3. Luas Lahan

\begin{tabular}{llcc}
\hline \multirow{2}{*}{ No. } & \multirow{2}{*}{ Luas lahan } & \multicolumn{2}{c}{ Jumlah } \\
\cline { 3 - 4 } & & Frekuensi & $\%$ \\
\hline 1. & Kurang dari 1 Ha & 28 & $53,8 \%$ \\
\hline 2. & 1 Ha & 17 & $32,7 \%$ \\
\hline 3. & Lebih dari 1 Ha & 7 & $13,5 \%$ \\
\hline
\end{tabular}

Sebagaian petani kopi yang tergabung dalam LMDH memiliki luas garapan seluas 1 Ha yang diberikan oleh pihak PERHUTANI untuk digarap dengan syarat tanpa merusak kelestarian wilayah hutannya. Letaknya berada di daerah hutan sehingga dalam pemanfaatannya, harus menaati peraturan tentang kehutanan.

Lahan di wilayah Desa Mekarjaya sebagian besar berbentuk bukit dan gunung. Untuk lahan yang ditanami tanaman kopinya sendiri sebagian besar berupa pegunungan karena lahannya terletak di daerah hutan.

Tabel 4. Bentuk Lahan Garapan

\begin{tabular}{llcc}
\hline \multirow{2}{*}{ No. } & \multirow{2}{*}{ Bentuk lahan } & \multicolumn{2}{c}{ Jumlah } \\
\cline { 3 - 4 } & & Frekuensi & $\%$ \\
\hline 1. & Datar & 6 & $11,5 \%$ \\
\hline 2. & Berbukit-bukit & 9 & $17,3 \%$ \\
\hline 3. & Pegunungan & 37 & $71,2 \%$ \\
\hline
\end{tabular}

Lahan perkebunan kopi di Desa Mekarjaya lebih didominasi oleh lahan dengan bentuk pergununan karena sebagian besar penanamannya dilakukan di daerah hutan yaitu lahan datar. Oleh karena itu, lahan tersebut dilindungi oleh PERHUTANI agar 
tidak terjadi pemanfaatan lahan secara berlebihan yang merugikan.

Berdasarkan tabel 5 lahan yang digarap oleh para petani kopi bukan seluruhnya milik sendiri, ada juga yang memang diberi tanggung jawab oleh PERHUTANI dan ada juga yang yang hanya menjadi buruh tani di tanah milik orang lain. Lahan yang merupakan milik PERHUTANI ada sekitar $55,8 \%$ lebih dominan dibandingkan lahan milik sendiri sebanyak $34,6 \%$

Tabel 5. Kepemilikan lahan

\begin{tabular}{llcc}
\hline \multirow{2}{*}{ No. } & \multirow{2}{*}{ Kepemilikan lahan } & \multicolumn{2}{c}{ Jumlah } \\
\cline { 2 - 4 } & & Frekuensi & $\%$ \\
\hline 1. & Milik sendiri & 18 & $34,6 \%$ \\
\hline 2. & Warisan & 5 & $9,6 \%$ \\
\hline 3. & Sewa & - & - \\
\hline 4. & $\begin{array}{l}\text { Milik pemerintah } \\
\text { (PERHUTANI) }\end{array}$ & 29 & $55,8 \%$ \\
\hline
\end{tabular}

\section{Alasan menjadi petani kopi}

Menjadi petani merupakan salah satu mata pencaharian paling utama di daerah pedesaan. Salah satu hal yang menyebabkan tanaman kopi lebih dipilih untuk dijadikan tanaman yang ditanam di lahan garapan para petani yaitu karena menguntungakan. Hal tersebut dapat dilihat pada tabel 6 .

Tabel 6. Alasan menanam kopi

\begin{tabular}{llcc}
\hline \multirow{2}{*}{ No. } & \multirow{2}{*}{ Alasan } & \multicolumn{2}{c}{ Jumlah } \\
\cline { 3 - 4 } & & Frekuensi & $\%$ \\
\hline 1. & Aturan & 12 & $23,1 \%$ \\
& PERHUTANI & & \\
\hline 2. & Menguntungkan & 23 & $44,2 \%$ \\
\hline 3. & Ikut orang lain & 16 & $30,8 \%$ \\
\hline 4. & Kondisi lahan & 3 & $5,8 \%$ \\
\hline
\end{tabular}

Berdasarkan tabel 6 alasan utama para petani menanam kopi ialah karena faktor menguntungkan dengan frekuensi 23 atau $44,2 \%$. Tanaman kopi yang biasanya ditanam ada dua jenis yaitu kopi arabika dan kopi robusta. Di Desa Mekarjaya sendiri jenis kopi yang paling banyak ditanam adalah kopi arabika seperti pada tabel 7

Berdasarkan tabel 7 kopi arabika lebih banyak ditanam dibandingkan dengan kopi robusta yaitu sebanyak $82,7 \%$ sedangkan kopi robusta lebih sedikit yaitu $17,3 \%$. Hal tersebut dikarenakan kopi arabika memiliki cita rasa yang lebih tinggi serta harga produksinya yang lebih tinggi pula dibandingkan kopi robusta. Selain itu, ketinggian lahan Desa Mekarjaya sesuai dengan karakteristik kopi arabika yaitu $1.200 \mathrm{mdpl}$.

Tabel 7. Kopi yang ditanam

\begin{tabular}{llcc}
\hline \multirow{2}{*}{ No. } & \multirow{2}{*}{ Jenis kopi } & \multicolumn{2}{c}{ Jumlah } \\
\cline { 3 - 4 } & & Frekuensi & $\%$ \\
\hline 1. & Arabika & 43 & $82,7 \%$ \\
\hline 2. & Robusta & 9 & $17,3 \%$ \\
\hline
\end{tabular}

Jumlah kopi yang dipanen bergantung pada luas lahan yang digarap. Semakin luas lahan yang ditanam kopi, hasil panen kopi pun semakin banyak karena tanaman kopi yang ditanam pun lebih banyak.

Tabel 8. Jumlah kopi dalam satu kali panen

\begin{tabular}{llcc}
\hline \multirow{2}{*}{ No. } & \multirow{2}{*}{ Jumlah kopi } & \multicolumn{2}{c}{ Jumlah } \\
\cline { 3 - 4 } & & Frekuensi & $\%$ \\
\hline 1. & $<1$ ton & 28 & $54 \%$ \\
\hline 2. & 1 ton & 16 & $30,8 \%$ \\
\hline 3. & $>1$ ton & 8 & $15,4 \%$ \\
\hline
\end{tabular}

Berdasarkan tabel 8 jumlah kopi yang dipanen dalam sekali panen berbeda-beda karena luas lahan yang dimiliki dan ditanami kopi pun berbeda-beda. Karena sebagian besar luas lahan yang digarap petani kopi yaitu kurang dari satu hektare maka jumlah kopi yang dipanen pun juga memang tidak terlalu banyak. Sekitar 54\% petani hanya mampu memanen kopi kurang dari satu ton.

\section{Pendapatan}

Beralihnya petani sayuran menjadi petani kopi bukan semata-mata tanpa alasan melainkan karena hal tersebut menyebabkan kebutuhan hidup dapat terpenuhi secara baik. Kurangnya pendapatan petani dari hasil penjualan tanaman sayuran yang digarapnya mencari solusi untuk mengatasinya yaitu dengan beralih menjadi petani kopi. Pendapatan yang dihasilkan dari bertani tanaman sayuran memang cukup rendah seperti pada tabel 9. 
Tabel 9. Pendapatan Petani Sayuran Sebelum Beralih Ke Tanaman Kopi

\begin{tabular}{llcc}
\hline \multirow{2}{*}{ No. } & \multirow{2}{*}{ Pendapatan } & \multicolumn{2}{c}{ Jumlah } \\
\cline { 2 - 4 } & & Frekuensi & \multicolumn{1}{c}{$\%$} \\
\hline 1. & $<\operatorname{Rp~500.000}$ & 36 & $69,2 \%$ \\
\hline 2. & Rp 600.000-Rp & 14 & $26,9 \%$ \\
& 1.000 .000 & & \\
\hline 3. & $\begin{array}{l}\text { Rp 1 1.100.000-Rp } \\
\text { 1.500.000 }\end{array}$ & 2 & $3,8 \%$ \\
\hline 4. & $>\operatorname{Rp~1.500.000~}$ & - & - \\
\hline
\end{tabular}

Tabel 9 menunjukkan bahwa lebih dari setengah responden petani sayuran sebelum beralih ke tanaman kopi terbilang masih kurang yaitu dengan mempunyai pendapatan $<$ Rp 500.000 yaitu sebayak 69,2\% sedangkan yang memiliki pendapatan tinggi lebih dari Rp 1.500.000 tidak ada sama sekali.

Tanaman yang ditanam sebelum beralih ke tanaman kopi cukup beragam seperti singkong, kol, tomat, cabai, dan lain-lain seperti pada tabel 10 .

Tabel 10. Tanaman Sebelum Kopi

\begin{tabular}{|c|c|c|c|c|}
\hline \multirow{2}{*}{ No. } & \multirow{2}{*}{\multicolumn{2}{|c|}{ Tanaman }} & \multicolumn{2}{|c|}{ Jumlah } \\
\hline & & & Frekuensi & $\%$ \\
\hline 1. & Singkong & & 3 & $5,8 \%$ \\
\hline 2. & Tomat & & 5 & $9,6 \%$ \\
\hline 3. & Cabai & & 8 & $15,4 \%$ \\
\hline 4. & $\begin{array}{l}\text { Sayuran } \\
\text { wortel, } \\
\text { bawang) }\end{array}$ & $\begin{array}{r}\text { (Kol, } \\
\text { kentang, }\end{array}$ & 36 & $69,2 \%$ \\
\hline
\end{tabular}

Berdasarkan tabel 10 dapat dillihat bahwa tanaman sayuran menjadi tanaman yang paling banyak ditanam sebelum beralih ke tanaman kopi yaitu sebanyak 69,2\% sedangkan untuk singkong sebanyak 5,8\%, tomat sebanyak $9,6 \%$, dan cabai sebanyak $15,4 \%$.

Setelah beralih ke tanaman kopi, terdapat perubahan pendapatan meskipun tidak secara signifikan. Pendapatan lebih meningkat dibandingkan ketika masih menjadi petani sayuran.

Tabel 11. Jumlah Pendapatan Bertani Kopi

\begin{tabular}{lccc}
\hline \multirow{2}{*}{ No. } & Pendapatan & \multicolumn{2}{c}{ Jumlah } \\
\cline { 3 - 4 } & & Frekuensi & $\%$ \\
\hline 1 & $<\operatorname{Rp~500.000~}$ & 17 & $32,7 \%$ \\
\hline
\end{tabular}

\begin{tabular}{llll}
\hline 2 & $\mathrm{Rp} \mathrm{600.000-Rp}$ & 24 & $46,1 \%$ \\
& 1.000 .000 \\
\hline 3 & $\operatorname{Rp~1.100.000-Rp~}$ & 8 & $15,4 \%$ \\
& 1.500 .000 & & \\
\hline 4 & $>\operatorname{Rp~1.500.000}$ & 3 & $5,8 \%$ \\
\hline
\end{tabular}

Berdasarkan data di atas, pendapatan penduduk mengalami peningkatan karena terlihat adanya petani yang memiliki penghasilan lebih dari Rp 1.500.000 sebanyak $5,8 \%$. Penghasilan tersebut dapat memenuhi setiap kebutuhan teruatama kesehatan dan pendidikan. Para petani mampu menyekolahkan anak-anaknya setidaknya hingga tingkat SMA. Dengan begitu dapat dikatakan bahwa beralihnya mata pencaharian petani sayur menjadi petani kopi itu menguntungkan.

\section{Pemasaran}

Pemasaran hasil produksi kopi dilakukan melalui pengepul yang berada di wilayah desanya. Namun, ada juga yang langsung menjual hasil produksi kopi tersebut kepada pembeli yang memang memiliki usaha bang kopi.

Tabel 12. Pemasaran Kopi Di Desa Mekarjaya

\begin{tabular}{lllcc}
\hline \multirow{2}{*}{ No } & \multirow{2}{*}{ Pemasaran } & \multicolumn{2}{c}{ Jumlah } \\
\cline { 3 - 5 } & & Frekuensi & $\%$ \\
\hline 1. & $\begin{array}{l}\text { Langsung } \\
\text { pengepul }\end{array}$ & ke & 39 & $75,0 \%$ \\
\hline 2. & $\begin{array}{l}\text { Langsung } \\
\text { pengolah }\end{array}$ & ke & 11 & $21,2 \%$ \\
\hline 3. & $\begin{array}{l}\text { Langsung } \\
\text { konsumen }\end{array}$ & ke & 2 & $3,8 \%$ \\
\hline
\end{tabular}

Tabel 12 menjelaskan bahwa para petani lebih memilih menjual kopi kepada pengepul karena mudah juga dekat jaraknya. Selain itu, kurangnya relasi menjadikan petani kurang mampu memasarkan hasil produksi kopinya dengan baik. Penjualan hasil produksi kopi di Desa Mekarjaya masih belum terdistribusi dengan leluasa, karena masih menjual kopi kepada pengepul yang ada di daerah tersebut. 
Tabel 13. Wilayah Pemasaran Kopi Desa Mekarjaya

\begin{tabular}{llcc}
\hline No. & \multicolumn{2}{c}{$\begin{array}{l}\text { Wilayah } \\
\text { pemasaran }\end{array}$} & \multicolumn{2}{c}{ Jumlah } \\
\cline { 3 - 4 } & Frekuensi & $\%$ \\
\hline 1. & Ke dalam desa & 41 & $78,8 \%$ \\
\hline 2. & Ke luar desa & 9 & $17,3 \%$ \\
\hline 3. & $\begin{array}{l}\text { Ke luar } \\
\text { kecamatan }\end{array}$ & 2 & $3,9 \%$ \\
\hline
\end{tabular}

Berdasarkan tabel 13 disebutkan bahwa cara penjualan kopi yang dihasilkan oleh para petani lebih dominan di jual ke wilayah desa yaitu sebanyak $78,8 \%$ sedangkan untuk ke luar desa dan kecamatan lebih sedikit yaitu sebanyak $21,2 \%$. kondisi tersebut dikarenakan kurangnya relasi dan pengepul yang ada di wilayah sekitar.

\section{Pembahasan Hasil Penelitian}

Berdasarkan analisis menyatakan bahwa faktor yang menyebabkan petani sayuran beralih menjadi kopi, menurut responden ialah karena faktor menguntungkan dengan presentase $44,2 \%$ yang terdapat pada tabel 6 . Tanaman yang ditanam sebelumnya ialah tanaman sayuran dengan presentase $69,2 \%$ yang terdapat pada tabel 10. Sedangakan tanaman kopi yang dominan lebih banyak ditanam ialah kopi arabika dengan presentase $82,7 \%$ yang terdapat pada tabel 7 .

Bentuk lahan yang paling banyak ditanami kopi ialah lahan berupa pegunungan dengan presentase $71,2 \%$ yang terdapat pada tabel 4. Lahan tersebut sebagian besar berada di wilayah hutan sehingga keberadaan dan pemanfaatannya diawasi oleh pihak LMDH beserta PERHUTANI agar kondisi lahan tetap terjaga. Faktor lain yang mempengaruhi yaitu bentuk lahan, dimana lahan yang digunakan untuk ditanami kopi berbentuk pegunungan.

Ketinggian lahan yang berada pada 1.200 mdpl mempengaruhi curah hujan pertahunnya, dimana berdasarkan data monografi desa mekarjaya memiliki curah hujan 3.545/tahun. Kondisi tersebut sangat cocok bagi hidupnya tanaman kopi. Lahan yang ditanami kopi rata-rata merupakan lahan garapan sehingga kandungan unsur hara di dalamnya sudah dapat terjamin bagi tanaman kopi. Beralihnya petani dari sayuran ke tanaman kopi mengalami peningkatan pendapatan seperti pada tabel 9 dan 11 .

Dalam penjualannya, petani lebih banyak memilih menjual ke pengepul dengan presentase $75 \%$. Penjualan tersebut juga dilakukan di wilayah desa saja karena kebetulan di desa tersebut terdapat seorang pengepul biji kopi. Hal tersebut dapat dilihat pada tabel 12 dan 13.

\section{SIMPULAN}

Berdasarkan hasil penelitian tentang "Faktor-faktor yang Mempengaruhi Alih Fungsi Mata Pencaharian Penduduk Dari Petani Sayuran Ke Tanaman Kopi Di Desa Mekarjaya Kecamatan Arjasari Kabupaten Bandung" dapat disimpulkan bahwa beralihnya mata pencaharian penduduk dari sayuran ke tanaman kopi dipengaruhi oleh beberapa faktor diantaranya yaitu kondisi lahan yang sangat sesuai dengan syarat tumbuhnya tanaman kopi khususnya kopi arabika berupa ketinggian, bentuk lahan, curah hujan, serta aturan PERHUTANI yang mengatur tentang kelestarian wilayah perkebunan agar tetap terjaga dan tidak rusak serta tercemar. Harga kopi di pasaran cukup tinggi dibandingkan dengan sayuran sehingga penduduk cukup tergiur pula untuk beralih ke tanaman kopi.

Penghasilan para petani dibilang lebih tinggi setelah mereka beralih menjadi petani kopi karena dapat menutupi kebutuhan hidup para petani termasuk kebutuhan pendidikan dan kesehatan. Penghasilan yang tinggi dapat dipengaruhi oleh kemampuan para petani dalam memasarkan hasil produksi kopi.

\section{REKOMENDASI}

Berdasarkan kesimpulan di atas penulis mencoba memberikan saran rekomendasi terhadap pemerintah dan masyarakat selaku petani di Desa Mekarjaya Kecamatan Arjasari Kabupaten Bandung adalah sebagai berikut:

1. Pemerintah agar memberi pengarahan secara rutin mengenai manfaat tanaman kopi baik bagi perekonomian maupun bagi kesehatan hutan. Mengingat bahwa wilayah Desa Mekarjaya merupakan wilayah perbukitan dan wilayah taninya sebagian besar pegunungan maka para petani harus memahami bagaimana cara 
menjaga serta memiliki pengetahuan mengenai jenis tanaman dan cara penanaman yang tepat.

2. Untuk petani di Desa Mekarjaya agar mampu memahami cara memilih jenis tanaman yang sesuai dengan kondisi lahan tanpa merusak kelestarian lingkungannya sebagai investasi untuk masa depan.

\section{DAFTAR PUSTAKA}

Arifin, Z. (2012). Penelitian PendidikanMetode dan Paradigma Baru. PT. Remaja Rosdakarya: Bandung.

Data Monografi Desa Mekarjaya.

Hestanto. Pengertian Pendapatan. [ONLINE].

https://www.google.com/amp/s/www.he stanto.web.id/pengertian-

pendapatan/amp/. Diakses pada 28 Agustus 2019.

Jamulya \& Yunianto, T. (1991). Kursus Evaluasi Sumberdaya Lahan (Tanah dan Survey Tanah). UGM Press: Yogyakarta.

Nurmala, T. Suyoso, A, D. Rodjak, A. Suganda, T. Natasasmita, S. Simarmata, T. Salim, E, H. Yuwariah, Y. Sendjaja, T, P. Wiyono, S, N dan Hasani, S. (2012). Pengantar Ilmu Pertanian. Graha Ilmu: Yogyakarta.

Peraturan Menteri Pertanian Republik Indonesia

Nomor/128/Permentan/OT.140/11/2014

/11/2012 Tentang Pedoman Teknis
Pembangunan Kebun Induk dan Kebun

Entres Kopi Arabika dan Kopi Robusta.

Rahardjo, P. (2012). KOPI (Panduan Budi Daya dan Pengolahan Kopi Arabika dan Robusta. Penebar Swadaya: Jakarta.

Saroyo, K, H. 2014 [ONLINE]. Jenis dan Karakteristik Kopi Arabika. Diakses dari: https://caswellscoffee.com/jenisdan-karakteristik-kopi-arabika/. Diakses pada 28 Agustus 2019.

Sudjana, N \& Ibrahim. (1989). Penelitian Dan Penilaian Pendidikan. Sinar Baru Algensindo: Bandung.

Suwarto \& Octavianty, Y. 2012. Budi Daya 12 Tanaman Perkebunan Utama. Penebar Swadaya: Jakarta.

Tika, P. 2005. Metode Penelitian Geografi. PT. Bumi Aksara: Jakarta.

Winarto, P. 2004. Memanfaatkan Tanaman Sayur Untuk Mengatasi Aneka Penyakit. PT. AgroMedia Pustaka: Tanggerang.

ANONIM. (2016). Pengertian Pertanian, Bentuk atau Jenis Pertanian. [ONLINE]. https://www.seputarpengetahuan.co.id diakses pada 28 Agustus 2019. 